\title{
Projeto Gerência de Trabalho e Inclusão Social de Usuários de Saúde Mental
}

Project Work Management And Social Inclusion Of Mental Health Patients

Proyecto Gerencia De Trabajo E Inclusión Social De Usuarios De Salud Mental

Ana Cecília Alvares Salis

Universidade Estácio de Sá
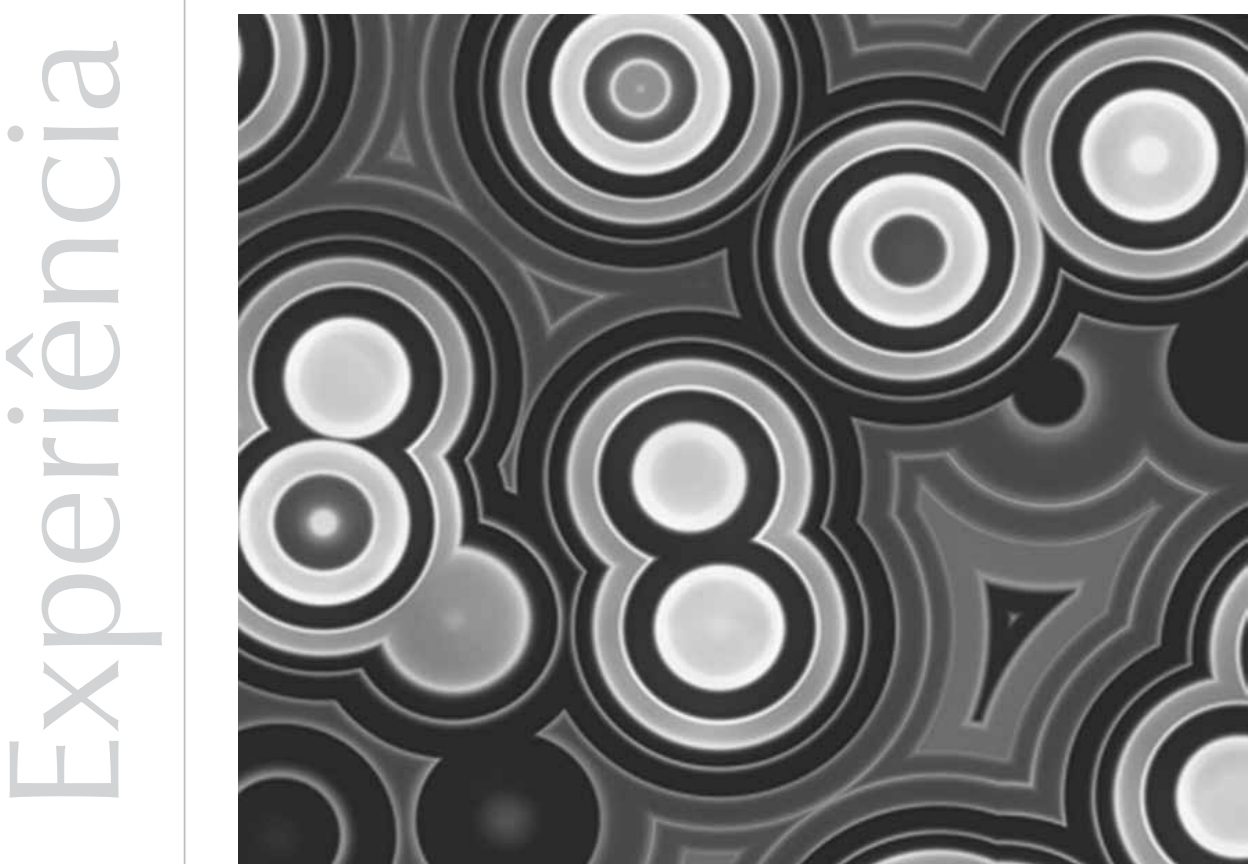
Resumo: Como proposta pioneira de inclusão social pela via do trabalho, o projeto Gerência de Trabalho apresenta-se como modelo de uma nova prática de cuidados no campo da saúde mental, e tem como objetivo estabelecer as condições de acesso e de permanência de pessoas com transtorno mental no mercado formal de trabalho. Partindo de diretrizes específicas, esse projeto não só investe na ampliação de possibilidades democráticas de inclusão social a usuários de saúde mental como também abre um novo campo de atuação para psicólogos.

Palavras-chave: Trabalho. Saúde mental. Inclusão social. Prática de cuidados.

Abstract: As a pioneering proposal for social inclusion through work, the Work Management project is presented as a new model of care practice in the mental health field, and it aims to establish the access conditions and the retention of people with mental disorders in the formal labor market. Starting with specific guidelines, this project does not only invest in the expansion of democratic possibilities of social inclusion to users of mental health care, but also opens a new field of work for psychologists. Keywords: Work. Mental health. Social inclusion. Care practice.

Resumen: Como propuesta pionera de inclusión social por la vía del trabajo, el proyecto Gerencia de Trabajo se presenta como un modelo de una nueva práctica de cuidados en el campo de la salud mental, y tiene como objetivo establecer las condiciones de acceso y de permanencia de personas con trastorno mental en el mercado formal de trabajo. Partiendo de directrices específicas, ese proyecto no sólo invierte en la ampliación de posibilidades democráticas de inclusión social a usuarios de salud mental sino también les abre un nuevo campo de actuación a los psicólogos.

Palabras clave: Trabajo. Salud mental. Inclusión social. Práctica de cuidados.

O projeto Gerência de Trabalho (PGT) foi desenvolvido com o objetivo de não só ampliar as ações de resgate da cidadania de pessoas com transtornos mentais (por meio do trabalho formal) bem como de oferecer às empresas a oportunidade de investir em novos conhecimentos sobre gestão de pessoas, propondo novas ações de responsabilidade social. Além disso, o PGT também abre um novo campo de atuação para profissionais de Psicologia bem como para a formação acadêmica de psicólogos.

Inspirado nos ideais da reforma psiquiátrica (italiana e brasileira) e no modelo norteamericano de emprego apoiado (support employment), o PGT quer apresentar-se como modelo de uma nova prática de cuidados no campo da saúde mental, cujo objetivo é cumprir com a difícil tarefa de incluir, de maneira coordenada e responsável, pessoas com transtorno mental no mercado formal de trabalho brasileiro, porque, a considerar as premissas que inviabilizam a empregabilidade dessa específica população no mercado formal, não foram poucos os entraves que se impuseram aos objetivos do PGT.
Como propor o ingresso dessas pessoas no mercado formal de trabalho se, no Brasil, há, desde o preconceito ao diagnóstico, passando pela rígida organização do trabalho nos modos de produção capitalista, até a falta de leis de proteção ao trabalho para essa população? Esses foram os primeiros desafios. E foi em resposta a eles que o PGT tratou de estabelecer as condições de sua viabilidade.

Será, então, por meio de metodologias de ação, inspiradas pelos seus propósitos de inclusão, que o PGT pretenderá assegurar: (1) o acesso de pessoas com transtorno mental ao mercado formal de trabalho (seja por mecanismos legais, seja pelo viés da responsabilidade social), (2) a justa adequação de interesses entre empregado/empregador (a partir de acordos formais com as empresas contratantes), (3) a necessária parceria com os dispositivos de saúde mental aos quais pertençam os usuários participantes do projeto (para que se faça o devido encaminhamento das questões pertinentes à saúde do trabalhador), e (4) a permanência dessas pessoas no emprego, desde a oferta de contratos por hora trabalhada (adequadas às reais condições de trabalho de cada 
Rinaldi (2006, pp. 141-148). Como cidadãos, somos todos iguais perante a lei, com direitos e deveres assegurados. uma delas) até o acompanhamento e o treinamento no próprio local de trabalho oferecido por um novo agente no campo, o gerente de trabalho.

Implantado pela primeira vez no Brasil, em 2005, na cidade de Nova Friburgo, RJ, o PGT contou ainda com o apoio institucional da iniciativa pública através da sua participação no projeto maior do Instituto Municipal Nise da Silveira (IMNS/RJ) de 2007 a 2009. Em 2008, deu início às suas atividades na empresa Prezunic Comercial Ltda, e, em 2009, ocorreu a sua contratação efetiva pela empresa.

O que este trabalho apresenta a seguir será a contextualização histórica da concepção do PGT, o detalhamento da proposta e os resultados quantitativos e qualitativos colhidos a partir da implantação do projeto na empresa Prezunic Comercial Ltda, em 2008, até a sua consolidação nos dias atuais.

\section{Trabalho e cidadania}

Desde a reforma psiquiátrica (considerado o movimento mais importante na história da psiquiatria por sua proposta de rompimento com práticas segregacionistas e de exclusão), muitos foram os investimentos em programas e projetos que envolviam estratégias de inclusão social. Uma delas diz respeito ao trabalho. É legítimo considerar o trabalho como importante veículo para a ratificação da cidadania. Por esse viés, articula-se uma rede de possibilidades de compartilhamento social, da qual se pode obter o reconhecimento pelo outro como igual.

Tal noção de igualdade, que está intrinsecamente ligada à concepção de cidadania, inclui certo anonimato ou apagamento do sujeito no que se refere a sua singularidade, segundo Rinaldi (2006, pp.141-148). Como cidadãos, somos todos iguais perante a lei, com direitos e deveres assegurados. Resta saber se, de fato, iniciativas privadas e políticas públicas dedicadas à causa da cidadania ao sujeito psicótico implicam necessariamente o apagamento de sua inscrição social como excluído. Dar-lhes voz quanto a seus direitos civis e sociais seria, assim, o ponto sensível da questão, e o trabalho vem aqui cumprir o seu papel.

Ainda que haja no Brasil, desde a década de 90, no contexto da reforma psiquiátrica, experiências importantes sobre trabalho e geração de renda para pessoas com graves transtornos mentais, de acordo com Leal (2008), há muito que se investir em conhecimento sobre a possibilidade efetiva de sua inserção no mercado formal de trabalho. Em outras palavras, trata-se de investir em experiências desvinculadas das propostas dos novos dispositivos substitutos do manicômio, tais como as oficinas de geração de renda, as cooperativas, as associações (movimento da economia solidária) ou quaisquer outras iniciativas restritas ao campo, conforme demanda de muitos usuários de saúde mental. Isso envolve o desafio que se concentra em não apenas estabelecer uma estratégia para garantir o acesso e a permanência dessas pessoas no mercado formal de trabalho (considerando suas peculiaridades e a ausência de leis de proteção ao trabalho para pessoas que possuam apenas transtorno mental), mas também o combate ao estigma, promovendo a aproximação dessa população ao corpo social, admitindo-a no mesmo patamar de igualdade quanto ao exercício de direitos e de deveres civis.

A proposta da Gerência de Trabalho, que detalho mais adiante, visa ao resgate da cidadania ao portador de transtorno mental, investindo em possibilidades reais para sua absorção no mercado formal de trabalho. Partindo de diretrizes específicas, que contemplam desde a contratação de estagiários de Psicologia para o acompanhamento de um usuário de saúde mental em seu próprio local de trabalho até o 
alinhamento entre ações do PGT, as empresas e os dispositivos de saúde mental, o projeto pretende estabelecer as condições para que se possa acolher essa mão de obra de maneira responsável e coordenada, admitindo a loucura apenas como diferença, e não como estado permanente de incapacitação.

\section{Contextualização da concepção do PGT}

Ao participar (2004-2006), a convite da Academia Brasileira de Ciências (ABC/RJ), do Programa Integrando como bolsista da Faperj, coordenei e supervisionei o Centro de Assistência a Moradias e Trabalho na Cidade de Nova Friburgo/RJ (CAMT/NF) para, à época, portadores de necessidades especiais (PNE). A partir dessa experiência, investi na causa do trabalho para pessoas com deficiência e/ou transtorno mental por meio do projeto Gerência de Trabalho.

Uma vez reconhecida essa experiência, fui convidada, pela iniciativa pública, para trabalhar no Instituto Municipal Nise da Silveira (IMNS, 2007-2009, RJ). Herdeiro de um dos mais antigos complexos manicomiais no Brasil - o Centro Psiquiátrico Pedro II (CPPII) -, o IMNS aderiu aos ideais da reforma psiquiátrica, e, na administração do Dr. Edmar Oliveira (2000-2009), foi implantada uma série de ações voltadas para a desinstitucionalização da loucura e a desconstrução de paradigmas no atendimento ao doente mental.

Se antes essa gigantesca estrutura hospitalar se ocupava do tratamento da doença mental, agora (desde a sua municipalização, em 2000) dedica-se à saúde e ao reconhecimento da cidadania de seus usuários. Tal fato se verifica não só na transformação de seus espaços físicos em residências terapêuticas, em alguns de seus serviços em Centros de Atenção Psicossocial (Caps), como também na oferta de projetos de inclusão social que contemplam a possibilidade de inserção no mercado de trabalho de seus usuários. Foi com esse objetivo que, a partir de minha experiência com o projeto Gerência de Trabalho em Nova Friburgo (RJ), fui convidada a participar da equipe de trabalho do IMNS.

Em agosto de 2007, fui contratada para coordenar o Núcleo de Geração de Renda do IMNS, tendo como ponto de partida a cantina Qui Deliche. Essa cantina, projeto idealizado pela direção do instituto, teria por objetivo ser o ponto de referência para a articulação de todas as ações voltadas para as oficinas de geração de renda da instituição, incluindo a divulgação de eventos e cursos, além de investir no projeto Gerência de Trabalho propriamente dito. Em meados de 2008, comemoramos nossa primeira grande parceria, no âmbito privado, com a aceitação do projeto pela Rede Prezunic de Supermercados/RJ.

Concluído em 2009 o meu contrato com o IMNS, e o primeiro ano de parceria entre o IMNS e o Prezunic, foi a partir do bom entendimento da proposta que a direção da empresa (setembro/2009) chamou para si a tarefa de apoiar essa iniciativa, contratando o projeto Gerência de Trabalho. Uma vez reestruturado e transformado em pessoa jurídica, será agora a empresa Ana Salis PGT Consultoria em Trabalho Assistido Ltda a prestar seus serviços ao Prezunic, incluindo usuários de saúde mental nos seus quadros funcionais.

Partindo dessa primeira contextualização, o projeto será agora apresentado desde as premissas conceituais até às condições de possibilidade para a sua concepção.

\section{A reforma psiquiátrica italiana e o pragmatismo norte- americano}

Ainda que reconhecidos, nas sociedades ocidentais capitalistas, os agenciamentos 
sociais e discursivos sobre a loucura - desde a medicina científica do século XVIII com Pinel (Tenório, 2002) -, o PGT vai tomar da invenção italiana e do pragmatismo norteamericano o seu ponto de partida.

Será pela via do entendimento de que a proposta reformista italiana de invenção (Basaglia como citado em Amarante, 1994) contempla a ruptura radical com alguns paradigmas da psiquiatria clássica que o PGT vem propor sua ação. É a partir da inclusão de um novo agente no campo (o gerente de trabalho) e da decisão de levar em conta os discursos dos próprios loucos quanto à simples vontade de trabalhar com carteira assinada (as CTPS) que o PGT sai em busca das condições para que isso aconteça. A invenção, somada ao pragmatismo, nesse caso, deu-se por uma ação afirmativa na construção de uma prática, a princípio, inexequível sob vários pontos de vista: desde a ausência de leis de proteção ao trabalho até a ausência de estratégias capazes de sustentar a proposta de permanência dessa população no emprego.

\section{Projeto Gerência de Trabalho (PGT) e o modelo norte- americano de emprego apoiado}

Para atender ao propósito de viabilizar a permanência de pessoas com transtorno mental no mercado de trabalho, o PGT vai tomar da experiência norte-americana de emprego apoiado a sua inspiração.

O projeto Gerência de Trabalho, que venho desenvolvendo nas cidades de Nova Friburgo e Rio de Janeiro (ambas no Estado do Rio de Janeiro), surgiu a partir de um treinamento obtido nos Estados Unidos em support employment, jobcoaches e cuidadores.
Como representante do Programa Integrando, da ABC/RJ (2004-2006), e pela parceria firmada para a troca de experiências entre brasileiros e norte-americanos, fui convidada a participar desse treinamento (80 horas), oferecido por organizações não governamentais (ONGs) norte-americanas a alguns membros de ONGs brasileiras participantes do programa.

O objetivo do treinamento foi colocar-nos em contato com as diferentes agências que oferecem, em grandes feiras, seus serviços e filosofia de trabalho aos clientes, portadores de deficiência e/ou transtorno mental. Assim, visitamos as seguintes agências: Abilities Network e The ARC of Montgomery County (primeira semana), CHI Centers Inc. e The ARC of Southern Maryland (segunda semana). Destas, a Abilities Network foi a que melhor atendeu às minhas expectativas, e, por essa razão, tomei-a como referência para a orientação de meu trabalho no Brasil.

Embora a proposta dessa agência se dirija, basicamente, às pessoas portadoras de epilepsia e autismo, além de crianças (não incluindo outros diagnósticos de transtorno mental), o diferencial nela observado nela foi o fato de colocar seus clientes em postos de trabalho formal, cumprindo horário alternativo (ou jornada diferenciada), utilizando os job coaches (gerentes de trabalho) em um esquema one-by-one, ou seja, cada cliente contratado por uma empresa, e apenas um a cada período de trabalho, seria acompanhado por um gerente de trabalho para o treinamento de tarefas exigidas em contrato. Isso implica a estratégia de não apenas oferecer o suporte necessário às demandas de cuidados a essas pessoas como também de não agrupá-las em um mesmo local, para facilitar a inclusão nos seus respectivos ambientes de trabalho. Aos job coaches caberia, então, a tarefa de acompanhar e treinar um cliente no próprio local de trabalho, de intermediar a relação entre este, os colegas de trabalho e o empregador, além de buscar postos de trabalho compatíveis com seus interesses. 
Com essa orientação, e contando com mais de 28 anos de lida com pacientes psiquiátricos, retornei ao Brasil com o firme propósito de trazer mais essa alternativa ao campo da saúde mental. Consciente do desafio que me aguardava, dei início a esse projeto observando as necessárias adaptações de um modelo norte-americano para sua utilização junto a pessoas com graves transtornos mentais em nosso contexto sociocultural. Há mais de sete anos, portanto, tenho essa experiência em curso, na intenção de pesquisar sobre o trabalho formal e seus desdobramentos no campo da saúde mental no Brasil.

A propósito das experiências de reinserção de pacientes com transtornos mentais graves no mercado de trabalho, Erotildes Leal, no $1^{\circ}$ Seminário de Trabalho e Geração de Renda: Construção de uma Rede (2002), apresentanos os quatro mais importantes modelos internacionais existentes: as experiências norte-americana, anglo-saxônica, francesa e italiana. Embora problematize cada uma delas em seus respectivos contextos, a autora aponta o modelo americano de emprego apoiado (utilizado pelo PGT) como uma das experiências mais efetivas na ajuda às pessoas com transtornos graves para obter e manter empregos competitivos. Essa perspectiva descrita pela autora deu ainda maior impulso à intenção de dar andamento a esse projeto no Brasil.

\section{Breve mapeamento histórico e primeiras condições de possibilidades para a implantação do projeto Gerência de Trabalho no Brasil}

Apesar de podermos resgatar na História a questão do trabalho no campo da psiquiatria desde o primeiro movimento reformista da República - a partir de 1920, considerando as primeiras colônias agrícolas em São Paulo e Rio de Janeiro como as precursoras da prática do trabalho como meio de tratamento e reabilitação, Guerra (2008) afirma que será a partir da década de 80 , em meio ao período de (re)democratização no País, mais precisamente a partir da aprovação da Lei no10.216/2001 (Tenório, 2002) que foram elaboradas, no Brasil, respostas mais efetivas quanto ao reclame à cidadania dos loucos. Das novas políticas do SUS, desde a progressiva desinstitucionalização da loucura - por meio da proposta dos novos dispositivos, ou dos Centros de Atenção Psicossocial (Caps) - ao direito às moradias assistidas, muito se fez ao longo dos últimos 20 anos no campo da saúde mental, e muito se evoluiu no sentido de devolver aos asilados o direito à vida extramuros. E foram essas as conquistas necessárias para que se pudesse hoje oferecer a proposta de PGT. Partindo de diretrizes que serão relatadas mais adiante, o PGT quer ouvir as demandas de trabalho formal por parte dessa população que ora é tutelada pelo diagnóstico de incapacidade laboral, ora é incapacitada para o trabalho pelo estigma social, pois foi sobretudo no enfrentamento a esses entraves com políticas públicas efetivas e com alguma significativa mudança no entendimento social quanto à loucura que se conquistou o alargamento dos espaços de circulação do louco para fora dos muros institucionais.

Para falar apenas do Município do Rio de Janeiro, foi a partir de setembro de 1995, quando a Secretaria Municipal de Saúde (SMS) assume a gestão plena do SUS na cidade, que uma série de providências quanto aos novos dispositivos de atenção em saúde mental foram tomadas. Em 1996, inaugurase o primeiro Caps no Município (Tenório, 2002), e, desde então, vai ampliando-se a rede até a configuração dos serviços residenciais terapêuticos, com a bolsa de incentivo à desospitalização (Resolução SMS no 942/2002). Esses resultados foram cruciais para que o campo e projetos sociais como 
o PGT pudessem cogitar do ingresso dessa população no mercado formal de trabalho, ou seja, foi a partir da conquista do direito à moradia e ao tratamento fora do asilo que se pôde oferecer essa via de acesso ao trabalho formal.

\section{Das primeiras restrições à possibilidade de implantação do PGT}

Situar qual a primeira grande dificuldade enfrentada para a implantação desse projeto seria tarefa bastante difícil. Portanto, de forma apenas esquemática, será primeiramente abordado o enfrentamento da questão legal que envolve a possibilidade de acesso dessa população ao mercado de trabalho formal.

\section{Do acesso...}

Sem medo de errar, poder-se-ia iniciar essa exposição afirmando que, se há alguma possibilidade de aceitação do PGT por uma empresa, esta reside no que se possa oferecer em contrapartida ao empregador; a aceitação de loucos em quadros funcionais inclui riscos, que a empresa só aceita por lei ou por um generoso compromisso com a responsabilidade social. O viés mais efetivo é, certamente, o cumprimento da lei.

No Brasil, qualquer empresa com mais de 100 funcionários é obrigada a disponibilizar de 2 a $5 \%$ de seus postos de trabalho para portadores de deficiência (Lei no 8.213/91, Art. 93). É o chamado plano de cotas obrigatórias. A consequência referente ao não cumprimento da lei acarreta multas, por vezes bastante desvantajosas para uma empresa. Considerando que apenas os portadores de transtorno mental não estão incluídos nessa lei, esse foi um ponto crucial a ser estudado para se cogitar o ingresso dos primeiros usuários em uma empresa. Foi a partir desse estudo que se descobriu a brecha necessária ao desfecho desse impasse. O Decreto no 5.296, de dezembro de 2004, Art. $5^{\circ}$, traz as seguintes definições:

Deficiência mental: funcionamento intelectual significativamente inferior à média, com manifestação antes dos dezoito anos e limitações associadas a duas ou mais áreas de habilidades adaptativas (...), d) Deficiência múltipla: associação de duas ou mais deficiências

$\mathrm{Na}$ associação entre esses itens, foi encontrada a maneira de se propor a inclusão dessas pessoas no plano de cotas às empresas, portanto, a primeira possibilidade protegida de acesso ao trabalho formal. Há muitos usuários de saúde mental que apresentam também quadros de deficiência(s) associados.

\section{...à permanência}

Vencido esse impasse, chega-se ao momento da apresentação da estrutura do projeto, em que o objetivo é estabelecer as condições de permanência de usuários de saúde mental em postos de trabalho. A PGT compreende que é absolutamente necessário o alinhamento entre ações de três instâncias, a saber: a empresa contratante, a coordenação do PGT e os serviços de saúde mental aos quais pertençam os usuários. Para que a proposta chegue a bom termo, faz-se necessário que:

As empresas contratantes viabilizem não só os contratos de trabalho contemplando jornadas diferenciadas (ou contratos por hora trabalhada) como também a contratação de estagiários para a função de gerentes de trabalho.

Os serviços de saúde mental trabalhem em estreita parceria com a coordenação do PGT, para que se possa dar os devidos encaminhamentos às demandas de cuidados por parte de seus respectivos usuários, quando as questões forem pertinentes a eventuais crises no trabalho. 
- A PGT coordene todas essas ações, além de orientar e supervisionar o trabalho dos gerentes de trabalho para o treinamento e o acompanhamento de cada usuário.

Em linhas gerais, esses seriam os pilares de sustentação do PGT, considerando que a pesquisa sobre seus efeitos está em curso. Cabe agora contextualizá-los no plano geral do projeto.

\section{Do suporte das empresas}

Diferentemente de outras propostas de encaminhamento ao mercado formal de trabalho, o PGT se caracteriza não apenas por dedicar-se a empregar usuários com transtorno mental mas também aqueles que em nenhuma hipótese poderiam ingressar no mercado de trabalho sem o devido suporte. Esses seriam os portadores de graves transtornos, que requerem atenção particular ainda que desejem, e possam, trabalhar com as suas carteiras de trabalho assinadas. Essa distinção é feita considerando que há muitos usuários até muito bem preservados que, apesar de conseguirem inserção profissional, perdem seus empregos por falta de apoio às suas dificuldades. Já os mais graves, ou com longo histórico de doença, não têm em seus perfis quaisquer características que os identifiquem à população economicamente ativa. No entanto, reúnem condições de trabalho, uma vez aceitas as limitações impostas pelo diagnóstico e que se aponte essa possibilidade. Portanto, aqui se privilegia o poder de contratualidade dessas pessoas, em franca oposição à tutela ideológica que os identifica como incapazes, ou irrecuperáveis (Baságlia como citado em Amarante, 1994, p. 63). Assim, a questão concentrar-se-ia na determinação da equação adequada para o ajustamento de interesses entre empregado e empregador, quando se propõe a contratação dessas pessoas.

É muito importante esclarecer que, quando apresentamos o projeto a uma empresa, não pedimos nenhuma espécie de favor ou de caridade. A intenção é a de oferecer mão de obra (tanto qualificada como orientada) em troca de um posto de trabalho. Contudo, considerando as peculiaridades dessa mão de obra, a proposta do PGT contempla o acordo de uma jornada de trabalho diferenciada contratações por hora trabalhada. É assim que os contratos podem variar de duas horas, duas vezes por semana (no caso de usuários com graves transtornos), até oito horas diárias, dependendo de cada caso. Isso implica salários compatíveis com o tempo de trabalho. Nesse caso, ainda que alguns deles recebam salários muito baixos, os ganhos subjetivos indicam que é superada a quantia recebida em dinheiro. Além disso, é possível ainda considerar que os que participam do projeto estejam em um mesmo patamar de igualdade em relação a qualquer outro funcionário, já que todos ganham exatamente a mesma quantia por hora de trabalho.

\section{Do suporte dos dispositivos de saúde mental}

Quanto ao alinhamento das parcerias, elas se fazem necessárias na exata medida em que o projeto depende não só do comprometimento de empresas e de políticas públicas, mas também de todos os dispositivos envolvidos com a causa do trabalho para pessoas com transtorno mental.

A proposta de estreito diálogo com os técnicos e os serviços de saúde mental a que pertençam os usuários em PGT é condição essencial. $\mathrm{O}$ entendimento dessa prática compreende a lógica do cuidado afastada do discurso propriamente terapêutico ou da clínica médica. Aqui, o trabalho quer respeitar essa atividade como franco exercício de vontade e de direito, e não como extensão de projetos terapêuticos. Os benefícios que forem alcançados pelo 
trabalho serão considerados ganhos comuns a todo trabalhador. As questões da clínica serão devidamente encaminhadas aos dispositivos que dela se ocupem.

\section{Do suporte dos gerentes de trabalho}

O gerente de trabalho (estudantes de Psicologia) é concebido como um novo agente cuja função será dedicar-se ao suporte necessário aos usuários para a execução de tarefas, além de intervir e de conhecer esse novo campo de trocas sociais, ou seja, ainda que se considere o necessário manejo clínico por parte da equipe de PGT, a sua diretriz de base é dedicar-se a viabilizar o trabalho com a orientação específica de encaminhar questões de tratamento para os serviços e os técnicos envolvidos com cada usuário.

Dedicada a promover o trabalho, o PGT pretende ater-se aos cuidados para que se possa dar acesso e sustentação ao emprego para usuários de saúde mental. Isso abrange estratégias que contemplam a loucura em sua positividade afirmativa, ainda que se considerem os devidos cuidados da clínica para a manutenção da possibilidade de trabalho e de convívio social.

\section{O PGT e o mercado formal de trabalho no Município do Rio de Janeiro}

Foi em resposta aos investimentos iniciais do projeto e do IMNS na intenção de colocar em andamento o PGT que, passados os seis primeiros meses do ano 2008, firmamos a primeira grande parceria com uma empresa privada, Prezunic Comercial Ltda/RJ. A direção dessa empresa interessou-se pelo projeto e, após verificar com o departamento jurídico a possibilidade de contração de funcionários horistas dentro do plano de cotas (considerando que todos tinham um quadro de deficiência associado), foi possível colocar os seis primeiros usuários do IMNS trabalhando com carteira assinada. Seguindo rigorosamente as orientações iniciais do projeto, no dia 06/08/2008, conseguimos, obter a contratação formal desses trabalhadores.

Respeitando as particulares condições de cada um deles, e ainda os princípios da proposta de inclusão da diferença nos espaços socialmente compartilháveis, procuramos distribuir os usuários em diferentes lojas da rede. Com isso, o que se intencionou foi não agrupá-los em um mesmo local para que não fossem identificados pela semelhança discriminatória da doença mental. Ao mesmo tempo, também não se pretendeu normalizar comportamentos que poderiam parecer bizarros ou estranhos ao grande público. O objetivo do PGT é apresentá-los com suas diferenças, mas mostrando que nem por isso são incapazes para o trabalho ou o convívio social. Distribuí-los, então, de maneira que as diferenças pudessem ser absorvidas individualmente pela equipe de trabalho e pela comunidade foi, para nós, uma importante estratégia de inclusão.

Assim, foi colocado em prática esse projeto em uma grande empresa, considerando que, de dezembro de 2008 até março de 2012, já contamos com o total de 46 usuários trabalhando com todos os seus direitos trabalhistas garantidos.

\section{Resultados quantitativos}

Na intenção de demonstrar a evolução desse trabalho, passamos a apresentar os resultados obtidos a partir de agosto de 2008, quando da implantação do PGT na empresa Prezunic Comercial Ltda, até os dias atuais. 


\section{Demonstrativo de crescimento do Projeto Gerência de Trabalho}

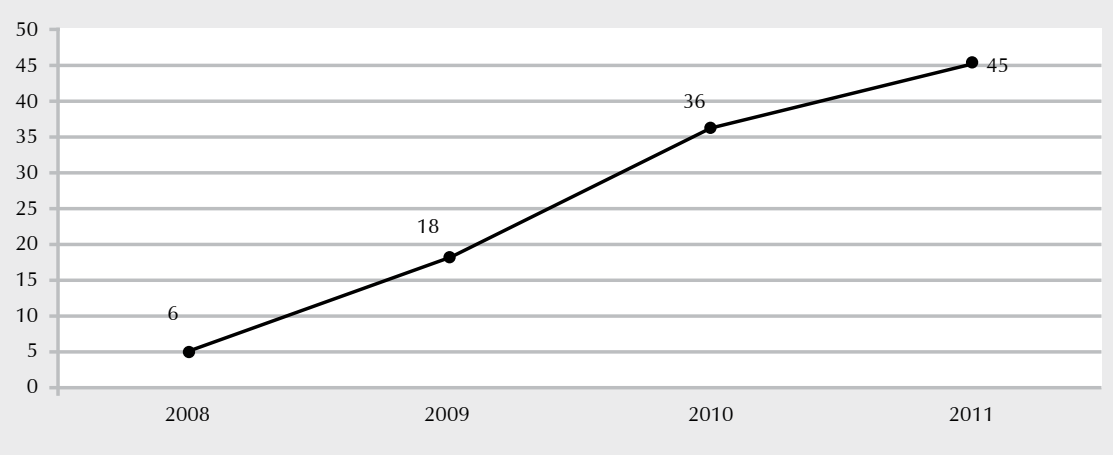

Gráfico 1. Crescimento do PGT de agosto de 2008 a agosto de 2011

* Valores de referência: mês de agosto de cada ano. Vale ressaltar que, até março de 2012, o total de participantes do projeto chegou a 46 usuários.

Esse gráfico exibe além do número de funcionários participantes do projeto (a partir da datareferência: agosto de cada ano), a consistência da parceria firmada entre as duas empresas, Ana Salis PGT e Prezunic, e o Ministério Público do Trabalho (MPT), principalmente após a assinatura do TAC. A partir dessa assinatura, a Ana Salis PGT pôde crescer significativamente no triênio 20082011, embora esse ciclo de crescimento (conforme prévio acordo com o MPT) esteja sempre limitado a algo em torno de $10 \%$ do número total de pessoas a serem contratadas dentro do plano de cotas da empresa. O objetivo dessa estratégia é contemplar a diversidade quanto à proteção ao trabalho para todas as pessoas consideradas, segundo a Convenção da ONU (2006/2008), em desvantagem social. Em outros termos, e em conformidade com headcount do Prezunic, a Ana Salis PGT contemplou, até outubro de 2011, 45 funcionários participantes do Projeto Gerência de Trabalho, e, até março de 2012, já contava com 46 funcionários.

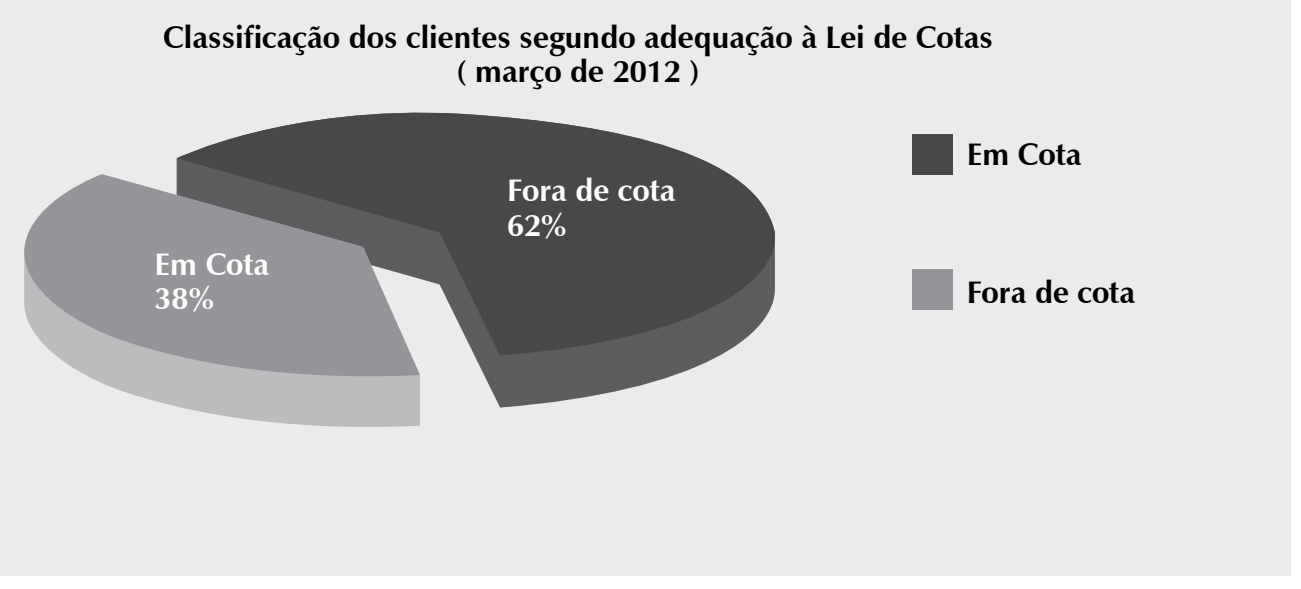

Gráfico 2. Quanto ao total de funcionários dentro e fora das cotas, temos atualmente os seguintes percentuais: 


\section{Classificação dos clientes segundo} o enquadramento funcional

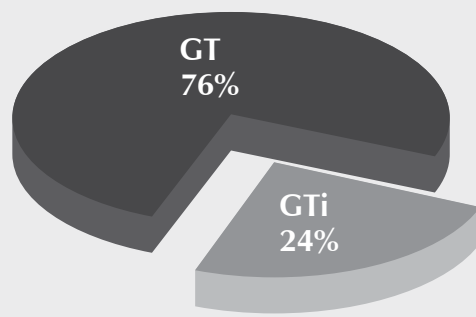

Gráfico 3. Por enquadramento funcional

Esse gráfico reafirma a importância da assinatura de um termo de compromisso da empresa com o MPT para a inclusão de pessoas com transtornos mentais no mercado formal de trabalho. Pela primeira vez, o panorama de desenvolvimento do projeto Gerência de Trabalho mostra que o número de trabalhadores com transtornos mentais fora das cotas é superior ao total de trabalhadores adequados às cotas.

Para esclarecermos a que universo o gráfico acima se refere, vale observar a tabela que se segue com dados gerais referentes à gestão de pessoas da Ana Salis PGT (2008/2012),

\section{Dados Gerais}

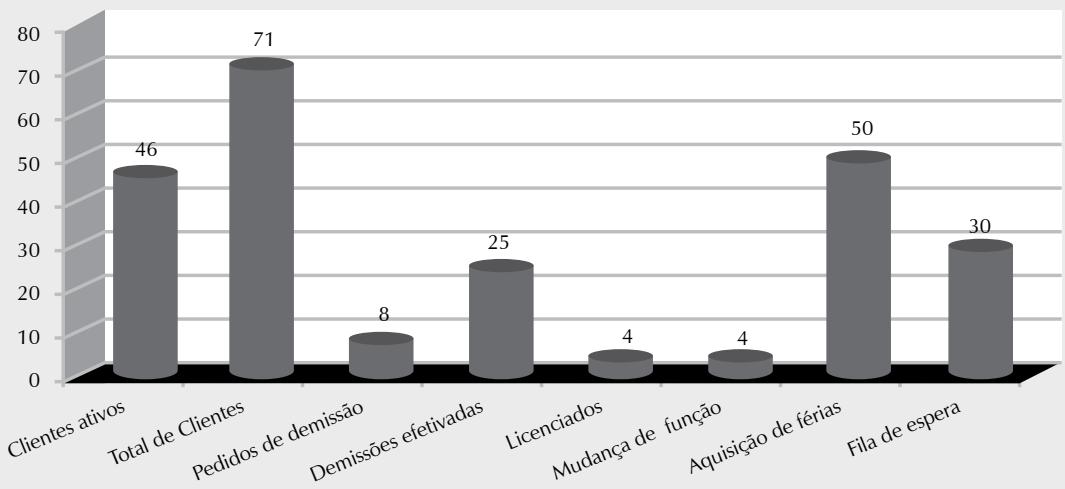

Gráfico 4. Dados gerais

Observa-se, nesse quadro, um baixo índice de rotatividade (turnover), indicando o desempenho favorável do acompanhamento prestado pela Ana Salis PGT na retenção desse tipo de mão de obra contratada pelo Prezunic. Em outras palavras, o acompanhamento sistemático de pessoas com 
transtornos mentais pelo PGT contribui para o índice global de turnover da empresa contratante. Outro aspecto importante consiste no fato de que, muitas vezes, as demissões efetivadas não redundam em um afastamento definitivo do funcionário da empresa. Nesses casos, ele continua sendo monitorado, pois trata-se de desligamentos estratégicos operados no sentido de auxiliar o funcionário em sua adesão ao tratamento (condição para participar do projeto).

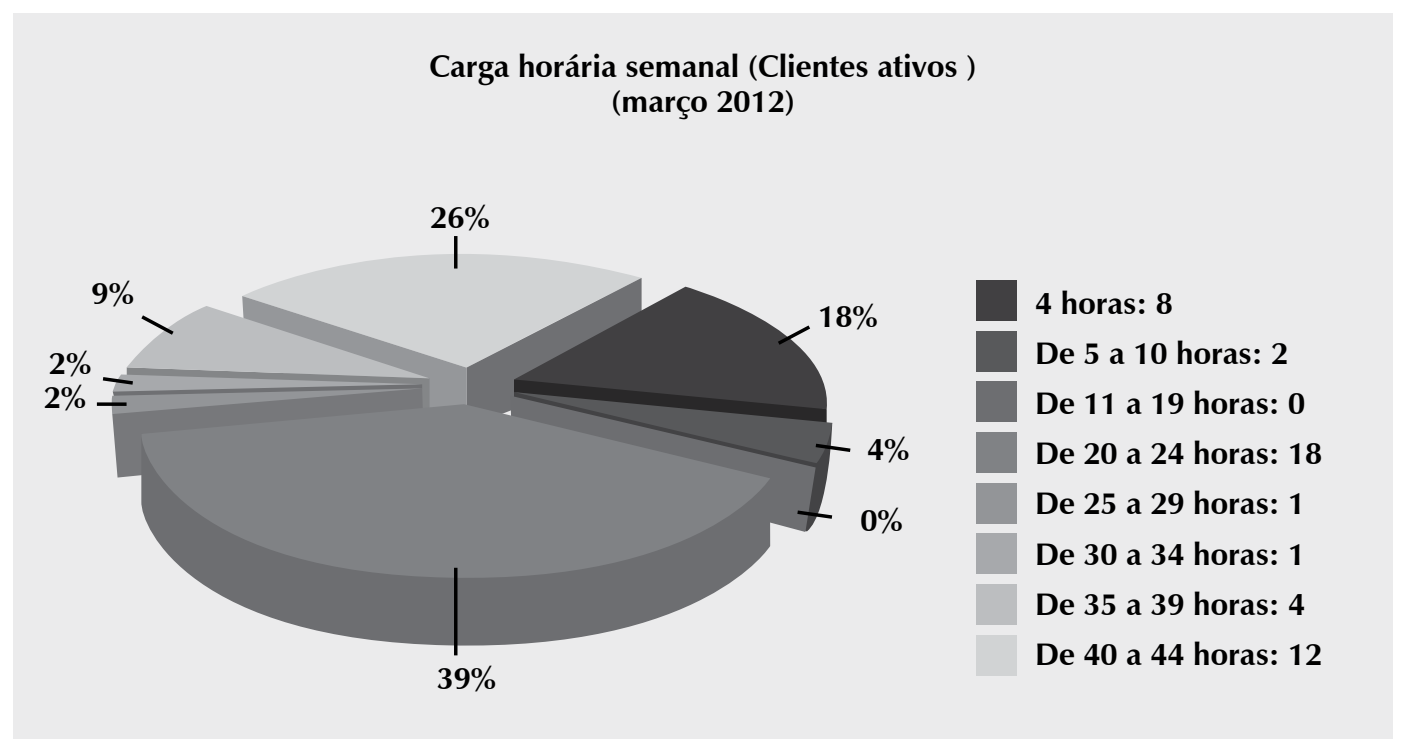

Grafico7. Demonstrativo por hora trabalhada

Outra diretriz de cuidados do PGT diz respeito à contratação de pessoas com transtornos mentais em jornadas de trabalho diferenciadas. É notória a constatação de que nem sempre essas pessoas têm condições de cumprir o horário regulamentar das 44 horas semanais de trabalho. Portanto, à coordenação do projeto, cabe estabelecer a carga horária adequada de acordo com as reais condições de trabalho de cada um dos participantes do projeto, ou seja, será sempre possível o aumento ou redução do horário de trabalho, de acordo com as demandas dos funcionários. O gráfico abaixo representa o universo atual dos participantes do PGT, segundo a carga horária semanal. Vale ressaltar que, pelo fato de serem horistas, as remunerações desses trabalhadores, assim como os respectivos encargos trabalhistas, são proporcionais ao número de horas trabalhadas.

\section{Resultados qualitativos}

As ações do projeto Gerência de Trabalho superaram limites, pois extraíram, do supostamente inexequível, tanto novas possibilidades de atuação para psicólogos no campo da saúde mental como novas experiências de gestão de pessoas nas empresas. Além disso, o projeto também foi motivação para incluir uma nova cláusula nos Termos de Ajustamento de Conduta, o que possibilitou o ingresso protegido de pessoas com apenas (sem o diagnóstico de deficiência associado) transtorno mental no mercado formal de trabalho.

No inequívoco reconhecimento a esse trabalho, no mês de novembro de 2010, a empresa Prezunic teve a honra de receber o prêmio Ser Humano (edição 2010), na categoria média/grande empresa, promovido pela $\mathrm{ABRH} / \mathrm{RJ}$, concorrendo com o case Projeto Gerência de Trabalho: uma Estratégia de Inclusão Social pela Via do Trabalho. 
Quanto ao fomento às políticas públicas, em mais uma inédita iniciativa do MPT/RJ, foi registrado em ata de audiência:

Aos doze dias de mês de abril de 2012, às $14 \mathrm{~h} 05$, na sede da Procuradoria do Trabalho da 1a Região, com as presenças das Procuradoras do Trabalho Lisyane Chaves Motta e Luciana Tostes de Guadalupe e Silva, no interesse do Procedimento Promocional no 002290.2011.01.000/3, foi inaugurada a reunião para ressaltar o papel instrumental do Procedimento Promocional, e registra-se desde já a premissa para atuação institucional de que estão incluídas nas cotas das empresas (Lei no 8213) pessoas com transtorno mental na forma da Convenção da ONU sobre os direitos da pessoa deficiente, de 2006/2008.

Considerando a experiência de inclusão de usuários de saúde mental na empresa Prezunic Comercial Ltda. (projeto Gerência de Trabalho), o setor supermercadista foi o eleito para expedir notificação recomendatória dando conta da nova situação, ou da inclusão nas cotas de pessoas com transtorno mental.

Essa foi, definitivamente, a iniciativa pública brasileira mais importante quanto ao ajustamento de medidas protetivas a uma população historicamente excluída da possibilidade legal de exercer sua cidadania por meio do trabalho formal. O MPT/RJ, ao incluir usuários de saúde mental na Lei no 8213/91 (conforme critérios da Convenção de 2006/2008), fez com que o Estado do Rio de Janeiro saísse na frente na defesa de direitos aos usuários de saúde mental no que toca à questão do ingresso no mercado formal de trabalho.

E é com muito orgulho que temos no PGT uma das referências motivadoras para essa iniciativa do MPT/RJ.

\section{Conclusão}

A tomar a história da loucura no Ocidente e as diretrizes da reforma psiquiátrica no Brasil, vê-se que a militância clínica e política na reconstrução de paradigmas para a compreensão e a atenção ao usuário de saúde mental é ainda tarefa árdua para os profissionais envolvidos nesse processo. Mesmo considerando importantes avanços na busca por alternativas ao enclausuramento do louco em espaços protegidos, ainda assim faltam-nos alguns passos para afirmar a loucura em sua positividade criativa e para promover o pleno exercício da liberdade a esses cidadãos. Considerando o distanciamento forçado e imposto a esses sujeitos na partilha do contrato social, restanos continuar na luta pela representação de seus potenciais interesses. É assim que a busca por tornar possível a essa população o ingresso responsável no mercado formal de trabalho traz a possibilidade de revertermos um ponto crucial para a aceitação e a inclusão da loucura na compreensão do corpo social como diferença, e não como incapacitação. É com essa intenção que o PGT traz, e quer compartilhar, a sua experiência de inclusão, a expectativa de que possamos ampliar ainda mais alguns novos paradigmas de cuidados aos usuários de saúde mental no Brasil, capazes de assegurar-lhes o pleno exercício da cidadania. 


\section{Ana Cecília Alvares Salis}

Pós-Graduada em Teoria Psicanalítica pela Universidade Estácio de Sá, Rio de Janeiro - RJ - Brasil.

E-mail: anasalis@gmail.com

Endereço para envio de correspondência:

Avenida Prefeito Dulcídio Cardoso, 1350, ap. 606, bl. 2, Barra da Tijuca. CEP: 22620-311. Rio de Janeiro, RJ.

Recebido 16/05/2012, Aprovado 11/04/2013.

Amarante, P. (1994). Uma aventura no manicômio: a trajetória de Franco Basaglia. História, Ciências, Saúde - Manguinhos, 1(1), 61-67.

Convenção da ONU sobre Os Direitos das Pessoas com Deficiência, (2006). Recuperado em 20 de março, 2013 de http://portal.mec.gov.br/index.php?option=com docman\&task=doc_download\&gid $=424$ \&ltemid.

Decreto no 5296/2004 (2004). Regulamenta as Leis $n^{\text {os }} 10.048$, de 8 de novembro de 2000, que dá prioridade de atendimento às pessoas que especifica, e 10.098, de 19 de dezembro de 2000, que estabelece normas gerais e critérios básicos para a promoção da acessibilidade das pessoas portadoras de deficiência ou com mobilidade reduzida, e dá outras providências. Recuperado em 20 de março, 2013 de http://www.planalto.gov.br/ccivil_03/_ato2004-2006/2004/ decreto/d5296.htm.

Guerra, C. M. A. (2008). Oficinas em saúde mental: percurso de uma história, fundamentos de uma prática. In M. C. Costa \& A. C. Figueiredo (Orgs.), Oficinas terapêuticas em saúde mental: sujeito, produção e cidadania. Rio de Janeiro: Contra Capa.
Leal, M. E. (2008). Trabalho e reabilitação psiquiátrica fora do contexto hospitalar. In M. C. Costa \& A. C. Figueiredo (Orgs.), Oficinas terapêuticas em saúde mental: sujeito, produção e cidadania. Rio de Janeiro: Contra Capa.

Lei 8213/1991 (1991, 24 jul.). Dispõe sobre os Planos de Benefícios da Previdência Social e dá outras providências. Recuperado em 20 de março, 2013 de http://www.planalto. gov.br/ccivil_03/leis/l8213cons.htm

Rinaldi, D. (2006). Entre o sujeito e o cidadão: psicanálise ou psicoterapia no campo da saúde mental? In S. Alberti \& A. C. Figueiredo (Orgs.), Psicanálise e saúde mental: uma aposta. Rio de Janeiro: Companhia de Freud.

Tenório, F. (2002). A reforma psiquiátrica brasileira, da década de 1980 aos dias atuais: história e conceito. História, Ciências, Saúde - Manguinhos, 9(1), 25-59. 